\title{
Perezhivanie and Its Application within Early Childhood Science Education Research
}

\author{
Nikolaos Christodoulakis ${ }^{1}$ (D) Clara Vidal Carulla ${ }^{2}$ and Karina Adbo ${ }^{1, *}$ \\ 1 Department of Biology and Environmental Sciences, Linnaeus University, 35195 Växjö, Sweden; \\ nikolaos.christodoulakis@lnu.se \\ 2 Department of Education, Communication and Learning, Gothenburg University, 40530 Gothenburg, \\ Sweden; clara.vidal.carulla@gu.se \\ * Correspondence: Karina.Adbo@lnu.se
}

Citation: Christodoulakis, N.; Vidal Carulla, C.; Adbo, K. Perezhivanie and Its Application within Early Childhood Science Education Research. Educ. Sci. 2021, 11, 813. https://doi.org/10.3390/educsci 11120813

Academic Editor: Konstantinos Ravanis

Received: 19 October 2021 Accepted: 11 December 2021 Published: 15 December 2021

Publisher's Note: MDPI stays neutral with regard to jurisdictional claims in published maps and institutional affiliations.

Copyright: (c) 2021 by the authors. Licensee MDPI, Basel, Switzerland. This article is an open access article distributed under the terms and conditions of the Creative Commons Attribution (CC BY) license (https:// creativecommons.org/licenses/by/ $4.0 /)$.

\begin{abstract}
Perezhivanie is a concept that was originally defined by Vygotsky, but it did not become a part of educational theory until recently. Today the concept has been revived, and it is now used as a way to include emotional aspects into education and educational research. The concept also provides a rationale for describing and forming personalised learning. The present study provides a literature review with the aim of covering the variety in definitions of the concept, as well as the different perspectives that the concept lends to research in general, and to research with focus on early years education in particular. Results show that the concept has been applied within the most common theoretical perspectives in use today (such as social, cultural and subjective perspectives) with an interesting array of outcomes, such as design of educational methods, analysis of different modes of experiencing and development of self-awareness. The use of this concept becomes a shift toward more emotional perspectives of learning and development that may not be altogether positive, as perezhivanie holds the risk of blurring the border between psychotherapy and education, which is something that would provide new challenges for education in general and especially for teacher education.
\end{abstract}

Keywords: early childhood; perezhivanie; science education

\section{Introduction}

Perezhivanie is a concept that was defined in Vygotsky's work [1,2]. In its most general sense, it is a concept that has been used to describe the reasons for individual differences, in what people focus on and how they then interpret this information [3]. Despite its potential importance for educational theory, the concept was only recently revived in contemporary research literature.

Today, the concept is used for holistic analysis of learning and development, as it provides a way to move beyond the dualism between the individual and the community [4-7]. This is a concept that could place focus on subjectivity in both learning and development but may also hold the promise of far more overarching conclusions of what may affect learning over the course of a lifetime [8]. The concept provides the logic to describe personalised learning outcomes, something that not only may help us gain insight regarding what children learn today, but also provide a rationale for analysing past and future learning [8]. The concept has been interpreted, developed and used by many researchers over the last decade, and in this process, it has diversified [9]. The purpose of this literature review is to explore the contemporary literature that includes the concept of perezhivanie. The aim is to find the diversity of applications and what the concept has to offer to educational research in general and to early years education in particular. 


\section{Background}

As with many concepts, perezhivanie has been altered along the way, but in all its diversity, there are two characteristics which are generally accepted. The first one is that perezhivanie is generally used to understand individual differences in what people focus on and how they then interpret this information. Perezhivanie means to understand "how a child becomes aware of, interprets and emotionally relates to a certain event" [10]. These individual interpretations are not seen as merely reflections of the external world, but instead as transformations, that is, products of creative internal activity, as refractions [11]. The concept can be used for describing why the same situations are interpreted in different ways by different people.

The second aspect relates to the processes through which perezhivanie itself changes. Changes in perezhivanie are suggested to be the result of emotionally charged experiences leading to changes in the way in which we relate to the surrounding environment. In current literature, various expressions have been used to refer to these emotionally charged experiences, such as "dramatic perezhivanie" [12], "predicament" [8] and "experiencing-asa-struggle" [13]. The origin of these emotionally charged experiences may be both coincidental and consciously planned as in education or through psychoeducation, psychotherapy and art. Examples of coincidental perezhivanie are found in unplanned, life-changing events, such as living in exile or growing up with alcoholic parents [8]. Conscious perezhivanie can be planned activities that become the driving force of children's motivation [14].

\section{Method}

A Web of Science search was performed on the 9 of April 2021 with the word "perezhivanie" as the topic. The search rendered 98 hits. From these ninety-eight papers, twenty-one were excluded (see Table S1). The reasons for exclusion were the language (three were written in Russian, one in Portuguese, and one in Spanish), the type of text (eight consisted of just an introduction or a short commentary) or because they were irrelevant to the goal of the present review (eight). The eight articles deemed irrelevant were omitted because they diverged from the goal of understanding how perezhivanie is currently situated in Early Childhood Education. Three articles were related to concurrent problems of acting in the context of Stanislafki's theory [15-17]. Other topics were learner readiness of security officers-to-be [18], the issue of national and cultural self-determination of L.S. Vygotsky [19], the notion of soperezhivanie [20] and a statistical analysis between professional well-being and risk of turnover in early childhood professionals [21].

Nine articles, which did not show up in the Web of Science search, but were relevant to the purpose of this review were introduced manually. These articles were added because they provided essential information about the notion of perezhivanie [12,22], play-worlds [23-28], and the theoretical work of Rey [29].

The first article included was published in 2003, with an increasing number of published works over the ensuing seven years, and the highest number of articles, 24, was published in 2016 (see Figure 1).

A thematic analysis [30] was used for categorising the articles as described in Table 1:

Table 1. Means for establishing trustworthiness at each phase of the thematic analysis.

\begin{tabular}{ll}
\multicolumn{1}{c}{ Phases of Thematic Analysis } & \multicolumn{1}{c}{ Means of Establishing Trustworthiness } \\
\hline Phase 1. Obtaining data & Store raw data in well-organised archives \\
Phase 2. Generating initial codes & Researcher triangulation \\
Phase 3. Searching for themes & Diagrams making sense of theme connections \\
Phase 4. Reviewing themes & Test for adequacy returning to raw data \\
Phase 5. Defining and naming the themes & Team consensus on themes \\
Phase 6. Producing the report & Describing the analysis process in detail \\
\hline
\end{tabular}




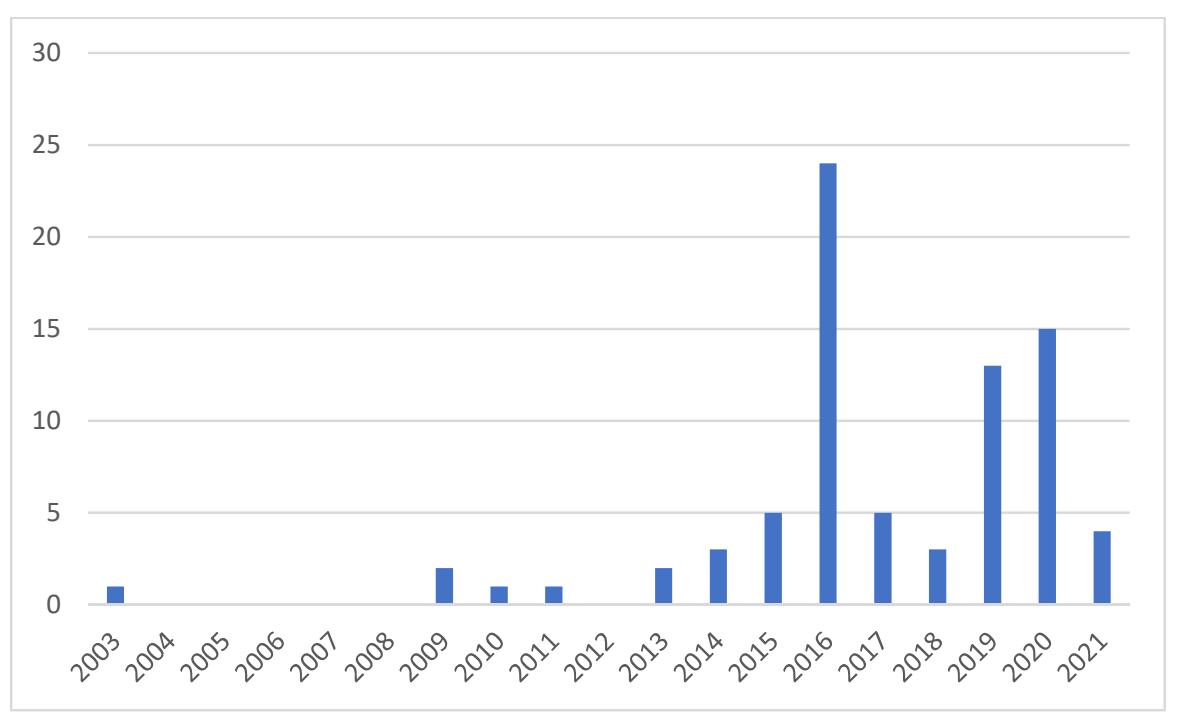

Figure 1. Number of papers from the literature search that were published each year.

After the literature search, initial codes were generated by an initial familiarisation of the remaining 85 papers. Three major categories were derived based on the kind of theoretical perspective used, with the first category being the social perspective ( 26 articles). This category included all articles in which perezhivanie was described as a social event. The sociocultural perspective (10 articles) included articles in which perezhivanie was connected to cultural mediation. The category called the subjective perspective ( 28 articles) included all articles in which the individual's internal interplay of meanings was in focus. Some articles that included both the sociocultural and the individual approach were defined as mixed ( 9 articles). Seven articles could not be categorised in any of these three categories due to the originality of the content. This initial analysis was performed separately by two of the authors, and then the results were compared.

To make sense of similarities within categories as well as connections between categories, a range of different parameters were used, such as direct reference theorists, use of concepts, as well as the methodological choices made by the different authors.

For example, the articles categorised in the social perspective conceptualised perezhivanie in the same manner as Veresov and Fleer [4]. Here, perezhivanie is used in connection with the concepts of the general genetic law of human development, the social situation of development, the real-ideal form, and the notion 'dramatic perezhivanie' [11]. The articles categorised in the sociocultural perspective conceptualised perezhivanie in the same manner as Ferholt, Nilsson and Clara [31,32]. Perezhivanie is here used in connection with the concepts of symbolic mediation, cultural artifacts, and the social construction of reality. The articles categorised in the individual perspective were mostly influenced by the works of Rey, Roth \& Jornet, and Poole \& Huang [33-35]. Here, perezhivanie is linked to subjective senses, subjective configurations and funds of identity.

The articles were then divided into observational research and intervention-based research, and a second analysis was conducted to ascertain the different ways perezhivanie has been operationalised in the literature and to test the categories for adequacy. Then, a third analysis was performed of the 22 articles that were focused on early childhood studies, and consensus on the categories was reached.

\section{Results}

\subsection{Observational Research Papers}

4.1.1. Research within the Social Perspective: Social Roles

In the social perspective, perezhivanie is identified in combination with concepts such as the general genetic law of human development, the social situation of development, the real-ideal form and the notion 'dramatic perezhivanie' [11]. The social environment is 
here seen as the source of personality and perezhivanie as formed by emotionally significant events, events that are instigated by the social environment. In this perspective, a child's perezhivanie is a combination of all the significant events that occurred in his/her past. The fields that are explored in this perspective are emotional regulation, school transition, role-playing games, children's scientific thinking, and science and technology in education.

Observational research mostly influenced by this theoretical perspective highlights the social character of experiencing and learning. Here, terms such as "role adjustment", "social identity", and "reader identity" are used for referring to how children "acquire behaviour patterns (i.e., behaviour adjustment), build emotional identification of the roles (i.e., emotional adjustment) and learn how to position themselves within a group (i.e., social adjustment)" [36,37]. In educational research in particular, it describes specific socially instigated events that cause change. The actual changes themselves include moving from a self-centered behaviour to a collaterally-centered behaviour [38,39], development in the way children conceptualise natural phenomena [40] or a change from "self-focused" toward "child-focused perezhivanie" when describing parental development [41]. The social-emotional interactions that cause or influence changes have been described as social roles [39] and peer interactions with older children, parents or teachers [39]. Also, one's personal sense of belonging to a group holds social meaning, and this can be a cause for change [42], as well as playing computer games together, where the difference between real-life and game characters is seen as a source for change [43].

4.1.2. Research within the Sociocultural Perspective: Perezhivanie as the Result of Mediated Cultural Representations

In the sociocultural perspective, the world is viewed as a sociocultural environment, meaning that everything has a meaning and carries cultural content. Here perezhivanie is connected to the concept of mediation. Within this perspective the individual does not form a direct relationship with the environment; instead, "the subject's agency is mediated by cultural means in the transformation of the object" [31]. Signs, concepts, discourses, cultural representations, traditions and artifacts can function as mediating tools. Perezhivanie then stresses how the cultural context determines how people signify their experiences. Research mostly influenced by this theoretical perspective describes what effect cultural representations have on individuals' experiences. No educational research was found within this perspective; instead, experiences, such as death, have been explored. For example, different cultures' representations of death can affect the emotional content of that experience. The difference between "my mother doesn't exist anymore and I will never see her again," or "my mother is now in heaven and is observing me" can have substantially different emotional outcomes for the individual [31,44]. Fields which are explored in this analysis are emotion regulation and special education.

\subsubsection{Research within the Individual Perspective: Perezhivanie as an Inner Production}

In the subjective perspective, the notion of social environment is abandoned, and perezhivanie is seen as an inner production, a creation based on subjective senses and configurations $[33,34,45]$. Perezhivanie is seen as varying "depending on which characteristics of personality are at play in the given situation" [46]. The subjective senses used in each situation define the content of perezhivanie. Research within this perspective acknowledges that a person exhibits a tendency of interpreting different things in a similar manner. In other words, subjective senses express themselves in patterns. These patterns of making sense are called subjective configurations. Within this theoretical perspective, perezhivanie is seen strictly as an individual phenomenon, which cannot be generalised to other individuals. An individual experience cannot be attributed to other people. A representative example of this kind of research appears in the field of early childhood education [47], in which researchers explored how a pacifier becomes an artifact of interchanging meanings between different actors. The pacifier becomes a sign of posessivity, discipline or a form of teaching social interaction. This interchange was the product of the specific circumstances and the individual meanings which were at play. 


\subsection{Intervention-Based Research Papers}

4.2.1. Research within the Social Perspective: Play as a Motivational Environment/ Pedagogical Instrument

Researchers influenced by the social perspective apply perezhivanie in experimental research as a pedagogical instrument. Here, the researcher's goal is to create a situation that will become a significant experience or dramatic event for the learner. Scientific playworlds is one example of a pedagogical method that focuses on children's interests and emotional connections [23]. The methodology of scientific play-worlds has been used for the purpose of teaching engineering and STEM in preschools [24-26,48] as well as for the adult population. Results show that the method has successfully been applied to change an individual's stance towards science [49] and to develop executive functions [50,51] and science concepts [14].

4.2.2. Research within the Cultural and the Individual Perspectives: Drama as a Method for Exploring Modes of Experiencing

Similar to research derived from the social perspective, research derived from the sociocultural and subjective perspectives used perezhivanie to develop pedagogical methods for educational purposes. Drama or "fantasy-based struggles" [52] or fairy tales [53] are two of the methods developed for including emotional experiences. The goal of these methods is not to explore subject-specific knowledge, but instead to promote or cultivate self-reliance and self-confidence [27]. Topics such as fear, security, loneliness, racism, marginalisation and the feeling of being worthless or denied are common [28,54]. Conflicts are embedded inside the storyline, and the method supports children in experiencing the unknown in a secure, fictional environment. This perspective also includes research on disorders within the autistic-spectra, where research following similar methodology supported children in their exploration of the environment without having emotional crises [55].

\subsubsection{Research within the Individual Perspective: Cultivating Self-Awareness}

The present analysis identified a distinct group of experimental research inspired for the most part by the individual perspective. Similar to the other perspectives, perezhivanie relates to an emotional experience that provokes new ways of thinking about a situation $[8,56]$. Reworking emotional experience is one approach used for overcoming a traumatic experience. Researchers, inspired by this aspect of perezhivanie, attempt to operationalise it in concrete experiments in the form of cultivating self-awareness abilities. In the educational context, research results show that it would be valuable for children, educators, and adults to receive training for developing their self-reflection processes. Reflective journals [57,58], collaborative forums $[59,60]$ or group writing conferences [61] are methods suggested to help teachers in their self-reflection [62,63].

In research focused on children, methods like drawing self-portraits [64] and using avatars [65] have been found to contribute to children's emotional regulation [31,66,67]. This line of research has the goal of helping teachers "know their students as complex, creative, and competent individuals with pasts and futures" [35,68]. Children's subjectivity is also explored here through the use of avatars [65] with the aim to develop self-understanding, identity [64] and emotional control [67].

As perezhivanie is connected to learning and development, much of the research conducted comes from early years learning. An analysis of the results derived from this research is important for understanding the contemporary use of the concept.

\subsection{Early Childhood Education Papers}

The content covered within the 22 articles related to early childhood research was analysed to explore what specific aspects perezhivanie contributes, especially to research in early years education. In general, the concept has provided early years education with means to explore children's individual, emotional interpretations of events and to focus 
on the emotional contribution to development. Secondly, it has been used for deriving educational methods. The first category, that of development, includes the development of executive functions (Ef) [51], social relations [69] during the transition between educational levels $[39,69,70]$ or cultural transitions $[36,39,42]$, emotional regulation [41], teachers' professional development $[20,59,63,71]$ and the development of scientific concepts $[40,72]$.

The second category of research involves educational methods for creating meaningful learning situations [55], a category that focuses on contextualised learning situations for creating common meanings [47] and positive emotional involvement from groups of children through the use of fairy tales [19], games [73], play-worlds [73], and role play [55]. Using perezhivanie as the unit of analysis does indeed provide a fine-grained level of analysis, which when applied to early years education can help educators to support the development of emotional regulation and positive attitudes toward different topics. Some of these results are described in the following sections.

\subsubsection{Development of Executive Functions}

Results show the use of play-worlds and the teacher's role for developing children's executive functions $(\mathrm{Ef})$. Executive functions include working memory, inhibitory control and cognitive flexibility, aspects that are seen as essential for school readiness. Play-worlds are here suggested as important frameworks for the development of Efs in particular, since discussions of the events in the play-world provide means for children to think deliberately of their role and to make plans. Research has shown that in the context of imaginary play, children trained their working memory as they were capable of adopting new game rules as a result of the roles they undertook. Similar results were facilitated with the ability to inhibit and self-regulate [51]. Imaginary play also allows teachers to embed problems and extended discussions make the children remember plots/roles and rules [73], all of which support the development of Efs.

\subsubsection{Development through Social Relations}

A series of different studies have been performed, and analysis of play-dates shows the importance of both individual and collective aspects of social interactions. Supporting individual children to learn social roles like taking turns and waiting for each other is important, since the individual affects the collective and the collective the individual. The inclusion of the child into planning play-dates gives agency to the child and provides them opportunities to discuss both the content and social interactions within the play-date. Other studies have shown that children as young as toddlers interact with familiar objects, such as pacifiers, and create shared meaning through imitations of movements and gestures [47].

\subsubsection{Development through Cultural Transitions}

Children in either transitions between educational levels or transitions between countries may experience emotional crisis that can bring about development. Events like unpacking familiar toys in a new country have been studied, and results show that the event may be a positive experience for one child as the old toys may hold symbolic meaning for the child, while for another child familiar things in a new environment produces a more negative emotional crisis [42]. Research concerning bi-cultural transitions to school does indeed emphasise the subjective interpretations by showing how children from the same culture have different emotional and cultural experiences as well as cognitive understandings. Results show that subjective analysis is important to support the individuals' transitions better [36,70] and that every transition is unique from the child's perspective [69]. Transitions especially signify potential crisis, and crisis handled the wrong way can be harmful for learning and development [69].

\subsubsection{Development through Professional Development}

Here, emotional aspects of early years teachers were studied for several reasons. Emotional investments are important for early years educators, when at the same time 
personal feelings are difficult to combine with their professional role [63]. An approach for development of pedagogical practices that includes emotional aspects has been suggested. The approach involves collaborative forums where teachers video-record and together with other teachers analyse their communication; one result from this study was the importance of communicating with the children on their level [59]. Also, teachers' own experiences of their workplaces have been explored through the concept of wellness, and results show that this concept for the teachers is a combination of physical, cognitive, psychological and emotional aspects, as well as a balance between demands and resources [20].

\subsubsection{Emotional Development}

In early years education, much focus is placed on emotional development within this field of research and has been performed to explore parents' contribution to children's emotional development. Results show that parents' awareness of their emotional responses (affect in intellect), such as parents' awareness of their own anger, is an important aspect for emotional regulation, something that helps to support children's emotional development and shows the collective nature of the subject and the environment [41].

\subsubsection{Developing Educational Methods}

Results show the importance of the subjective aspects in learning experiences by revealing how role play created emotional experiences for one child and also provided an entry into the social world [55]. Other research projects use perezhivanie for designing emotionally connected learning situations; here, positive emotions are analysed through gestures and verbal expressions as well as body language. Results show that adults are keener to participate in games than play and that games can help change people's attitudes [34]. Other emotionally connected learning situations can involve creating environments of co-experiencing, where emotions like sadness or joy can be discussed and generalised through the use of fairy tales [39].

\subsubsection{Developing Scientific Concepts}

Results show children's personal descriptions of what is included in the concepts of clouds, where the starting point was metaphysical interpretations of divine intervention. With help, this description progressed toward the inclusion of sky and air and dust, and then further toward the inclusion of rain, drizzle and rainbows. Detailed analysis provides more and improved dynamic support for young children's learning and development [40].

\section{Discussion}

\subsection{Contributions of Perezhivanie to Contemporary Research in General}

There are two general aspects of perezhivanie that appear in the literature: (a) perezhivanie is used for understanding differences in what we focus on and how this event is interpreted, and (b) perezhivanie itself is changed by intentionally creating emotionally connected experiences. Indeed, perezhivanie is used in connection to learning, seen as a change, within all articles. The difference between the different theoretical perspectives in the operationalisation of perezhivanie provides means for focusing on various aspects, such as changes in social relations, changes by cultural mediations, or changes in the individual.

Research influenced by the social perspective situates perezhivanie within the context of social dynamics and places focus on social positioning or the development of pedagogical methods intentionally designed to create positive experiences of learning $[24,25,28]$. Here, the concept of perezhivanie provides a logic for intentionally affecting learning over a lifetime.

The sociocultural and subjective perspectives are sources of inspiration for experimental research, which lead to the result that the significance of perezhivanie was not to identify an experience, but rather to train all relevant actors in the educational context to be selfaware of their perezhivanie processes $[59,61]$. This line of research blurs the border between education and psychology, in the sense that it suggests that teachers and students should 
learn methods for self-exploration. The learning in focus here is emotional exploration, which may help in facing the challenges that education in general poses nowadays.

\subsection{Perezhivanie in Research Concerning Early Childhood Education}

Perezhivanie can be considered as a theoretical concept that allows the study of a broad array of aspects surrounding the child's development in general and science education in particular. It is a concept that re-establishes a connection between early years education and psychology, building a bridge between the two disciplines. This connection raises a series of questions regarding emotional and professional care, as well as questions regarding emotional development in general.

The concept has indeed become an important analytical tool to apply in early childhood research. The diversity of perspectives shows that the scientific community is still making progress toward understanding the notion of perezhivanie and experience. Considering this discussion with regard to early childhood education, the concept of perezhivanie is opening up a wide variety of research questions and problems [43]. There is extensive growth especially in early childhood education, signifying a turn towards processes of individual learning and subjectivity [47].

\subsection{Limitations to the Study}

By limiting the literature search to Web of Science, important contributions to current research may have been overlooked. The results may also have been affected by the fact that the categorisations were based on only two independent analyses.

Supplementary Materials: The following are available online at https:/ /www.mdpi.com/article/10 .3390/educsci11120813/s1. Table S1: Raw Data Table.

Author Contributions: Conceptualization, N.C., C.V.C. and K.A.; methodology, K.A.; validation, N.C., C.V.C. and formal analysis, N.C., C.V.C.; writing-original draft preparation, N.C., C.V.C. and K.A.; writing - review and editing, Karina Adbo; funding acquisition, K.A. All authors have read and agreed to the published version of the manuscript.

Funding: This research was funded by the Crafoord Foundation (12 July 2020).

Institutional Review Board Statement: Ethical review and approval were waived for this study, due to that it is a literature review.

Informed Consent Statement: Not applicable.

Data Availability Statement: Not applicable.

Acknowledgments: The authors would like to express our thanks for the invitation to this Special Issue and the feedback provided by the reviewers.

Conflicts of Interest: The authors declare no conflict of interest.

\section{References}

1. Vygotsky, L.S. The Psychology of Art; The MIT Press: Cambridge, UK, 1974.

2. Vygotsky, L.S. The Problem of the environment. In The Vygotsky Reader; van der Veer, R., Valsiner, J., Eds.; Blackwell Publishers: Cambridge, UK, 1994; pp. 338-354.

3. Fleer, M. An everyday and theoretical reading of perezhivanie for informing research in early childhood education. Int. Res. Early Child Educ. 2016, 7, 34-49.

4. Veresov, N.; Fleer, M. Perezhivanie as a theoretical concept for researching young children's development. Mind Cult. Act. 2016, 23, 325-335. [CrossRef]

5. Ng, C. Subject choice and perezhivanie in mathematics: A longitudinal case study. Educ. Stud. Math. 2021, 3, 547-563. [CrossRef]

6. Davis, S. Perezhivanie, art and creative traversal: A method of marking and moving through COVID and grief. Qual. Inq. 2020, 27, 767-770. [CrossRef]

7. Chen, F. Co-development of emotion regulation: Shifting from self-focused to child-focused perezhivanie in everyday parenttoddler dramatic collisions. Early Child Dev. Care 2020, 1-14. [CrossRef]

8. Blunden, A. Translating perezhivanie into English. Mind Cult. Act. 2016, 23, 274-283. [CrossRef] 
9. Poole, A. Re-theorising the funds of identity concept from the perspective of subjectivity. Cult. Psychol. 2020, 26, 401-416. [CrossRef]

10. Michell, M. Finding the 'prism': Understanding Vygotsky's perezhivanie as an ontogenetic unit of child consciousness. Int. Res. Early Child. Educ. 2016, 7, 5-33.

11. Veresov, N. Perezhivanie as a phenomenon and a concept: Questions on clarification and methodological meditations. Cult.-Hist. Psychol. 2016, 12, 129-148.

12. Veresov, N. Introducing cultural-historical theory: Main concepts and principles of genetic research methodology. Cult. Psychol. 2010, 4, 83-90.

13. Clarà, M. Vygotsky and Vasilyuk on perezhivanie: Two notions and one word. Mind Cult. Act. 2016, 23, 284-293. [CrossRef]

14. Ramos, M.V.; Renshaw, P. The contours of perezhivanie: Visualising children's emotional experiences in place. Cult.-Hist. Psychol. 2017, 13, 105-128.

15. Gothberg, M.; Bjorck, C.; Makitalo, A. From drama text to stage text: Transitions of text understanding in a student theatre production. Mind Cult. Act. 2018, 25, 247-262. [CrossRef]

16. Merlin, B. 'This side of reality': Thoughts and provocations regarding acting and Stanislavski. Stanisl. Stud. 2015, 3, 53-67. [CrossRef]

17. Weinbren, J. Re-Animating Stanislavsky: Realising aliveness in the virtual actor. Stanisl. Stud. 2020, 8, 123-142. [CrossRef]

18. Johansson, M.W. Expanding learner readiness of young Swedish security officers-to-be in upper secondary school. J. Vocat. Educ. Train. 2020, 72, 555-574. [CrossRef]

19. Sobkin, V.S.; Klimova, T.A. 'Lines of mourning': On the issue of national and cultural self-determination of L.S. Vygotsky. Cult.-Hist. Psychol. 2017, 13, 4-12.

20. March, S.; Fleer, M. Soperezhivanie: Dramatic events in fairy tales and play. Int. Res. Early Child 2016, 7, 68-84.

21. McMullen, M.B.; Lee, M.S.C.; McCornick, K.I.; Choi, J. Early childhood professional well-being as a predictor of the risk of turnover in Early Head Start \& Head Start settings. J. Res. Child Educ. 2021, 34, 331-345.

22. Veresov, N. Refocusing the lens on development: Towards genetic research methodology. In Visual Methodologies and Digital Tools for Researching with Young Children: Transforming Visuality; Fleer, M., Ridgway, A., Eds.; Springer: Cham, Switzerland, 2014; pp. 129-149.

23. Fleer, M. A tapestry of playworlds: A study into the reach of Lindqvist's legacy in testing times. Mind Cult. Act. 2020, 27, 36-49. [CrossRef]

24. Stephenson, T.; Fleer, M.; Fragkiadaki, G. Increasing girls' STEM engagement in early childhood: Conditions created by the conceptual playworld model. Res. Sci. Educ. 2021. [CrossRef]

25. Fleer, M.; Fragkiadaki, G.; Rai, P. Programmatic research in the conceptual PlayLab: STEM PlayWorld as an educational experiment and as a source of development. Sci. Educ. Res. Prax 2020, 76, 9-23.

26. Fleer, M. Engineering playworld-A model of practice to support children to collectively design, imagine and think using engineering concepts. Res. Sci. Edu. 2020. [CrossRef]

27. Lindqvist, G. The dramatic and narrative patterns of play. Eur. Early Child Educ. Res. J. 2003, 11, 69-78. [CrossRef]

28. Nilsson, M. Creative pedagogy of play-The work of Gunilla Lindqvist. Mind Cult. 2010, 1, 14-22. [CrossRef]

29. Patiño, J.F.; Goulart, D.M. Qualitative epistemology: A scientific platform for the study of subjectivity from a cultural-historical approach. Int. Res. Early Child 2016, 7, 161-181.

30. Nowell, L.S.; Norris, J.M.; White, D.E.; Moules, N.J. Thematic analysis: Striving to meet the trustworthiness criteria. Int. J. Qual. Methods 2017, 16, 1-13. [CrossRef]

31. Clarà, M. Representation and emotion causation: A cultural psychology approach. Cult. Psychol. 2015, 21, 37-58. [CrossRef]

32. Ferholt, B.; Nilsson, M. Perezhivaniya as a means of creating the aesthetic form of consciousness. Mind Cult. Act. 2016, 23, 294-304. [CrossRef]

33. Rey, F.G. Vygotsky's concept of perezhivanie in the Psychology of art and at the final moment of his work: Advancing his legacy. Mind Cult. Act. 2016, 23, 305-314.

34. Roth, W.M.; Jornet, A. Perezhivanie in the light of the later Vygotsky's Spinozist turn. Mind Cult. Act. 2016, 23, 315-324. [CrossRef]

35. Poole, A.; Huang, J. Resituating funds of identity within contemporary interpretations of perezhivanie. Mind Cult. Act. 2018, 25, 125-137. [CrossRef]

36. Ma, J. The complex trajectory of children's transition to school within a bi-cultural context: A case of a Chinese immigrant child in Australia. Eur. Early Child Educ. Res. J. 2019, 27, 81-99. [CrossRef]

37. Ng, C.; Renshaw, P. An indigeneous Australian student's perezhivanie in reading and the evolvement of reader identities over three years. Learn. Cult. Soc. Interact. 2019, 22. [CrossRef]

38. Sulaymani, O.; Fleer, M. Perezhivanie as a phenomenon and a unit of analysis for studying children's interactions with ipads in the early years of school in Saudi Arabia. Early Child Dev. Care 2019, 189, 255-269. [CrossRef]

39. Adams, M. Young expatriate children forming friendships: A cultural-historical perspective. Int. Res. Early Child. Educ. 2016, 7, 85-105.

40. Fragkiadaki, G.; Fleer, M.; Ravanis, K. A cultural-historical study of the development of children's scientific thinking about clouds in everyday life. Res. Sci. Educ. 2019, 49, 1523-1545. [CrossRef] 
41. Chen, F. Parents' perezhivanie supports children's development of emotion regulation: A holistic view. Early Child. Dev. Care 2015, 185, 851-867. [CrossRef]

42. Adams, M.; Fleer, M. Moving countries: Belongings as central for realizing the affective relation between international shifts and localized micro movements. Learn. Cult. Soc. Interact. 2015, 6, 56-66. [CrossRef]

43. Schmit, W.L. Perezhivanie and the study of role-playing games. Cult. Psychol. 2017, 23, 391-407. [CrossRef]

44. Smagorinsky, P. Vygotsky's stage theory: Examining teacher professional identity formation in the paired-placement of student teachers. Mind Cult. Act. 2011, 18, 319-341. [CrossRef]

45. Veresov, N.; Mok, N. Understanding development through the perezhivanie of learning. In The Routledge Handbook of Sociocultural Theory and Second Language Development; Poehner, M.E., Lantolf, J.P., Swain, M., Eds.; Routledge: New York, NY, USA, 2018; pp. 89-101.

46. Dang, T.K.A. Identity in activity: Examining teacher professional identity formation in the paired-placement of student teachers. Teach. Teach. Educ. 2013, 30, 47-59. [CrossRef]

47. Neves, V.F.A.; Katz, L.; Goulart, M.I.M.; Gomes, M.F.C. Dancing with the pacifiers: Infants' perezhivanya in a Brazilian early childhood education centre. Early Child Dev. Care 2020, 190, 558-569.

48. Fleer, M. How conceptual playworlds in preschool settings create new conditions for children's development during group time. Learn. Cult. Soc. Interact. 2021, 28. [CrossRef]

49. Fleer, M.; Adams, M.; Gunstone, R.; Hao, Y. Studying the landscape of families and children's emotional engagement in science across cultural contexts. Int. Res. Early Child 2016, 7, 122-141.

50. Fleer, M.; Veresov, N.; Walker, S. Playworlds and executive functions in children: Theorising with the cultural-historical analytical lenses. Integr. Physiol. Behav. Sci. 2019, 54, 124-141. [CrossRef] [PubMed]

51. Fleer, M.; Veresov, N.; Harrison, L.; Walker, S. Working with teachers' pedagogical strengths: The design of executive function activities for play-based programs. Australas. J. Early Child. 2017, 42, 47-55. [CrossRef]

52. Clarà, M. The many lives of the word perezhivanie. Mind Cult. Act. 2016, 23, 339-342. [CrossRef]

53. Fleer, M.; Hammer, M. 'Perezhivanie' in group settings: A cultural-historical reading of emotion regulation. Australas. J. Early Child. 2013, 38, 127-134. [CrossRef]

54. Tateo, L. Who wants to keep me a puppet? Pinocchio's tale as a metaphor of developmental processes. Mind Cult. Act. 2019, 26, 24-40. [CrossRef]

55. Davis, S.; Dolan, K. Contagious learning: Drama, experience and perezhivanie. Int. Res. Early Child. Educ. 2016, 7, 50-67.

56. Blunden, A. Vygotsky's idea of gestalt and its origins. Theory Psychol. 2011, 21, 457-471. [CrossRef]

57. Golombek, P.; Doran, M. Unifying cognition, emotion and activity in language teacher professional development. Teach. Teach Educ. 2014, 39, 102-111. [CrossRef]

58. Golombek, P.R. Redrawing the boundaries of language teacher cognition: Language teacher educators' emotion, cognition and activity. Mod. Lang. J. 2015, 99, 470-484. [CrossRef]

59. Quinones, G.; Li, L.; Ridgway, A. Collaborative forum: An affective space for infant-toddler educators' collective reflections. Australas. J. Early Child. 2018, 43, 25-33. [CrossRef]

60. Kim, M.S. Uncovering one trilingual child's multiliteracies development across informal and formal learning contexts. Euro Eur. Early Child. Educ. Res. J. 2016, 24, 414-438.

61. Mochizuki, N. The lived experiences of thesis writers in group writing conferences: The quest for 'perfect' and 'critical. J. Second. Lang. Writ. 2019, 43, 36-45. [CrossRef]

62. Engel, A.; Fauré, J.; Membrive, A.; Merino, I.; Coll, C. The influence of parents in the discursive construction of technologymediated learning experiences. Mind Cult. Act. 2019, 26, 323-335. [CrossRef]

63. Brennan, M. Perezhivanie and the silent phenomenon in infant care: Rethinking socioculturally informed infant pedagogy. Contemp. Issues Early Child. 2016, 17,317-327. [CrossRef]

64. Nogueira, A.L.H. Emotional experience, meaning and sense production: Interweaving concepts to dialog with the funds of identity approach. Cult.-Hist. Psychol. 2014, 20, 49-58. [CrossRef]

65. Poole, A. Funds of knowledge 2.0: Towards digital funds of identity. Learn. Cult. Soc. Interact. 2017, 13, 50-59. [CrossRef]

66. Renshaw, P. The consequences of ADHD diagnosis: Integrating scaffolding and perezhivanie to redesign pedagogy for ADHDdiagnosed children. Emot. Behav. Difficulties 2019, 24, 301-305. [CrossRef]

67. Shahri, M.N.N. The development of teacher identity, emotions and practice: Before and after graduation from a MA TESOL program. Systems 2018, 78, 91-103. [CrossRef]

68. Roth, W.M. The invisible subject in educational science. J. Curric. Stud. 2018, 50, 315-332. [CrossRef]

69. Ma, J. Qualitative change in social situation of development as the starting point of children's role adjustment during the transition to school. Early Child Dev. Care 2020, 190, 750-765. [CrossRef]

70. Salmi, S.; Kumpulainen, K. Children's experiencing of their transition from preschool to first grade: A visual narrative study. Learn. Cult. Soc. Interact. 2019, 20, 58-67. [CrossRef]

71. Coelho, C.M.M. Beyond perezhivanie, sense and language: An empirical study of early childhood teachers' subjective senses. Int. Res. Early Child. Educ. 2016, 7, 219-237. 
72. Fragkiadaki, G.; Ravanis, K. Genetic research methodology meets early childhood science education research: A cultural-historical study of child's scientific development. Cult.-Hist. Psychol. 2016, 12, 310-330.

73. Adams, M.; Fleer, M. Social inclusion and exclusion of a young child: A cultural-historical perspective of an international mid-semester transition into an international school in Malaysia. Australas. J. Early Child. 2016, 41, 86-94. [CrossRef] 